\title{
Correlates of sedentary behaviour among adolescents and adults with hazardous, harmful or dependent drinking in South Africa
}

\begin{tabular}{|c|c|}
\hline \multicolumn{2}{|c|}{$\begin{array}{l}\text { Authors: } \\
\text { Karl Peltzer } \\
\text { Nancy Phaswana-Mafuya }{ }^{3} \text { (I) } \\
\text { Supa Pengpid }\end{array}$} \\
\hline \multicolumn{2}{|c|}{$\begin{array}{l}\text { Affiliations: } \\
{ }^{1} \text { Department for } \\
\text { Management of Science and } \\
\text { Technology Development, } \\
\text { Ton Duc Thang University, } \\
\text { Ho Chi Minh City, Vietnam }\end{array}$} \\
\hline \multicolumn{2}{|c|}{$\begin{array}{l}{ }^{2} \text { Faculty of Pharmacy, Ton } \\
\text { Duc Thang University, } \\
\text { Ho Chi Minh City, Vietnam }\end{array}$} \\
\hline \multicolumn{2}{|c|}{$\begin{array}{l}{ }^{3} \text { Research and Innovation } \\
\text { Office, North West University, } \\
\text { Potchefstroom, South Africa }\end{array}$} \\
\hline \multicolumn{2}{|c|}{$\begin{array}{l}{ }^{4} \text { ASEAN Institute for Health } \\
\text { Development, Mahidol } \\
\text { University, Salaya, Thailand }\end{array}$} \\
\hline \multicolumn{2}{|c|}{$\begin{array}{l}\text { Corresponding author: } \\
\text { Karl Peltzer, } \\
\text { karl.peltzer@tdtu.edu.vn }\end{array}$} \\
\hline \multicolumn{2}{|c|}{$\begin{array}{l}\text { Dates: } \\
\text { Received: } 12 \text { Mar. } 2018 \\
\text { Accepted: } 28 \text { Mar. } 2019 \\
\text { Published: } 04 \text { July } 2019\end{array}$} \\
\hline \multicolumn{2}{|c|}{$\begin{array}{l}\text { How to cite this article: } \\
\text { Peltzer K, Phaswana-Mafuya N, } \\
\text { Pengpid S. Correlates of } \\
\text { sedentary behaviour among } \\
\text { adolescents and adults with } \\
\text { hazardous, harmful or } \\
\text { dependent drinking in South } \\
\text { Africa. S Afr J Psychiat. } \\
\text { 2019;25(0), a1217. https://doi. } \\
\text { org/10.4102/sajpsychiatry. } \\
\text { v25i0.1217 }\end{array}$} \\
\hline \multicolumn{2}{|c|}{$\begin{array}{l}\text { Copyright: } \\
\text { (C) 2019. The Authors. } \\
\text { Licensee: AOSIS. This work } \\
\text { is licensed under the } \\
\text { Creative Commons } \\
\text { Attribution License. }\end{array}$} \\
\hline \multirow{2}{*}{ 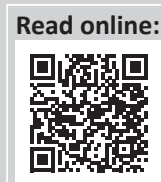 } & \\
\hline & $\begin{array}{l}\text { Scan this QR } \\
\text { code with your } \\
\text { smart phone or } \\
\text { mobile device } \\
\text { to read online. }\end{array}$ \\
\hline
\end{tabular}

Background: There is lack of information on the correlates of sedentary behaviour among persons with alcohol use disorders. The study aimed to examine socio-demographic and health correlates among adolescents and adults with hazardous, harmful or probable dependent alcohol use (= problem drinking).

Method: Data from the cross-sectional South African National Health and Nutrition Examination Survey (SANHANES-1) 2011-12 were analysed. From a total sample of 15085 persons aged 15 years and older, 2849 adolescents and adults (mean age $=37.1$ years, standard deviation [s.d.] = 15.1) were identified as problem drinkers, based on the Alcohol Use Disorders Identification Test-Consumption (AUDIT-C). Multivariable logistic and linear regression were used to determine the associations between socio-demographic characteristics, health variables and high sedentary behaviour ( $\geq 8 \mathrm{~h} /$ day) and total minutes of sedentary behaviour a day.

Results: The prevalence of high sedentary behaviour ( $\geq 8 \mathrm{~h}$ /day) was $11.9 \%$ overall (11.9\% among men and $12.1 \%$ among women), and the mean (s.d.) duration of sedentary behaviour was 263 (169) $\mathrm{min} /$ day. In bivariate analysis, older age, population group, functional disability, cognitive impairment, having hypertension, having had a stroke and posttraumatic symptoms were correlated with high sedentary behaviour. In adjusted logistic regression analysis, older age and being Indian or Asian were positively, and having been diagnosed with angina was negatively, associated with high sedentary behaviour. In linear regression analysis, older age, not employed and having had a stroke were positively, and being of mixed race and having angina were negatively, associated with total minutes (up to $960 \mathrm{~min} /$ day) of sedentary behaviour in a day.

Conclusion: The study provides socio-demographic and health correlates of sedentary behaviour among problem drinkers. This information can guide possible future interventions in reducing sedentary behaviour among problem drinkers.

Keywords: Sedentary behaviour; Problem drinking; Correlates; National survey; South Africa.

\section{Introduction}

Globally, harmful alcohol use ranks 8th among the 79 largest contributors to global disabilityadjusted life-years (DALYs). ${ }^{1}$ In South Africa, alcohol harm was responsible for an estimated 7.0\% of total DALYs and $7.1 \%$ of all deaths. ${ }^{2}$ Risky alcohol consumption (e.g. hazardous or harmful drinking $9.0 \%$ and binge drinking $14.1 \%$ ) has been found to be prevalent in South Africa..$^{3,4}$ Individuals who are hazardous, harmful or dependent alcohol drinkers (= problem drinkers) are at higher risk of physical illness (infectious diseases such as tuberculosis and non-communicable diseases such as cardiovascular disease and diabetes) and mental illness and mortality. ${ }^{5,6}$

Considering the limitations of various biological and psychological treatment approaches for alcohol use disorders, Vancampfort et al. ${ }^{7}$ stress the need for new interventions, such as physical activity, that may help in reducing alcohol intake as well as physical and mental comorbidity. ${ }^{8}$

'Sedentary behavior refers to any waking behavior characterized by an energy expenditure $\leq 1.5$ metabolic equivalent (MET) while in a sitting or reclining posture'. ${ }^{9}$ Among youth and adults significant evidence exists that sedentary behaviour, independently from the levels of physical activity, is associated with morbidity (hypertension, total cholesterol, cardiometabolic risk, type 2 diabetes and metabolic syndrome) and mortality. ${ }^{10,11,12}$ In a systematic review in youth, adult and

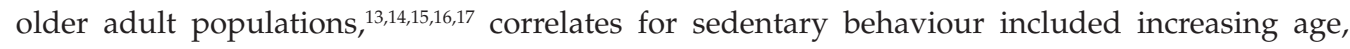


gender, education, employment status, income, obesity, smoking status, poor physical health and poor mental health (anxiety, depressive symptoms).

Considering the importance of sedentary behaviour interventions, that may differ in terms of correlates from physical activity interventions, ${ }^{13}$ there is a special need to target sedentary behaviour in special groups or vulnerable populations such as those who are problem drinkers. ${ }^{5}$ Because associations with sedentary behaviour among problem drinkers may differ to those in the general population, ${ }^{14}$ it is relevant to study correlates of sedentary behaviour among problem drinkers separately. Therefore, the study aimed to examine sociodemographic and health correlates among adolescents and adults with hazardous, harmful or probable dependent alcohol use (= problem drinking) in a national survey in South Africa.

\section{Methods}

\section{Sample and procedure}

The first South African National Health and Nutrition Examination Survey (SANHANES-1) is a cross-sectional and multistage population-based household health survey conducted in 2012. ${ }^{18}$ Participants were interviewed with a questionnaire on socio-demographic and health variables after their informed consent was obtained. The study protocol was approved by the research ethics committee (REC) of the HSRC (REC 6/16/11/11).

The survey response rate of participants was $92.6 \%$.

\section{Measures}

Sedentary behaviour was measured with two questions on the time sitting or reclining in the past 7 days during a usual weekday and usual weekend day. ${ }^{19,20}$ Responses were recorded in hours and minutes. Sedentary times were truncated at $960 \mathrm{~min} /$ day $(16 \mathrm{~h})$. Times spent sedentary were summed to calculate the total minutes per day in the last 7 days. ${ }^{20}$ High sedentary behaviour was defined as $\geq 8 \mathrm{~h} /$ day. ${ }^{10,21}$

Problem drinking was assessed with the three-item Alcohol Use Disorders Identification Test-Consumption (AUDIT-C), with scores of 3 or more in women and 4 or more in men indicating hazardous, harmful or dependent alcohol use (or problem drinking) $)^{22}$ (Cronbach's alpha 0.89).

Socio-demographic information included sex, age, population group, employment and residential status.

Self-rated health was assessed with the item: 'In general, how would you rate your health today?'18 Responses were dichotomised into having 'good health' (= 1: very good, or 2: good) or 'poor health' (=3: moderate, 4: bad or 5: very bad).

Functional disability was assessed with the item: 'Overall in the last 30 days, how much difficulty did you have with work or household activities?' Response options ranged from
$1=$ none, $2=$ mild, $3=$ moderate, $4=$ severe to $5=$ extreme ${ }^{18}$ Functional disability was defined as moderate to extreme difficulties.

Cognitive impairment was assessed with two items:

How much difficulty did you have with concentrating or remembering things?

How much difficulty did you have in learning a new task (e.g. learning how to get to a new place, learning a new game, learning a new recipe) $?^{18}$

Response options range from $1=$ none to $5=$ extreme. The two items were summed and cognitive impairment was defined as moderate to severe (scores 6-10).

Current tobacco use was assessed with two questions on daily or less than daily tobacco smoking and use of other tobacco products. ${ }^{18,23}$

Fruit consumption: 'How many fruits do you usually eat per day?' Vegetable consumption: 'How many portions of vegetables, excluding potatoes, do you usually eat per day?' Response options were $1=4$ or more per day, $2=1-3$ per day, $3=$ not every day, but 4 or more a week, $4=$ not every day, but less than 4 per week, and $5=$ none. $^{18}$

Handwashing hygiene behaviour was assessed with the question: 'How often do you wash your hands before eating?' Response options ranged from $1=$ always to $4=$ never. ${ }^{18}$

Bodily pains were measured with the question: 'How much bodily aches or pains did you have?' Response options ranged from $1=$ none to $5=$ extreme or cannot do. ${ }^{17}$ Bodily pains were defined as 'moderate, severe, extreme/can't do'.

Physical ill-health conditions were assessed with the question: 'Has a doctor or nurse or health worker at a clinic or hospital told you that you have had any of the following conditions? High blood pressure, stroke, heart disease, a heart attack or angina (chest pains), high blood cholesterol, high blood sugar or sugar diabetes, and tuberculosis' ${ }^{18}$

Visual difficulties were assessed with two questions asking about the difficulty of near and distant vision. Response options ranged from $1=$ none to $5=$ extreme or cannot do. ${ }^{18}$ Both questions were summed and visual difficulty was defined as 'moderate, severe, extreme/can't do' (scores 6-10).

Hearing difficulties were assessed with two items about the difficulty in 'hearing someone talking on the other side of the room in a normal voice' and 'hearing what is said in a conversation with one other person in a quiet room'. Response options ranged from $1=$ none to $5=$ extreme or cannot do. ${ }^{18}$ Both questions were summed and hearing difficulty was defined as 'moderate, severe, extreme/can't do' (scores 6-10).

Sleep problems were measured with the item: 'How much of a problem did you have with sleeping, such as falling asleep, 
waking up frequently during the night, or waking up too early in the morning?' Response options ranged from $1=$ none to 5 = extreme/cannot do. Sleeping problems were classified in response to this question as 'moderate', 'severe' or 'extreme/cannot do' ${ }^{24}$

Psychological distress in the past month was assessed with the 10 -item Kessler 10 scale, $^{25}$ and has been validated in South Africa. ${ }^{26}$ Response options ranged from $1=$ never to $5=$ all of the time and the total score is a summation of all the responses, with scores of 20 or more indicating mild, moderate or severe psychological distress. ${ }^{25}$ Cronbach's alpha for the Kessler 10 scale was 0.91 in this sample.

Posttraumatic stress disorder (PTSD) was assessed with the 17-item Davidson Trauma Scale (DTS) that assesses all primary DSM-IV symptoms of PTSD related to intrusion, avoidance and hyperarousal symptoms. Participants were considered to have PTSD 'if they score at least one re-experiencing, three avoidance/numbing and two hyperarousal phenomena at a frequency of at least twice in the previous week' ${ }^{27}$ In this analysis, we used any of the three symptom criteria (Cronbach's alpha 0.94).

\section{Data analysis}

Data were analysed with STATA software version 13.0 (Stata Corporation, College Station, TX, USA). Descriptive statistics were calculated for the proportions of the study variables. Pearson chi-square statistics was used to test for differences in proportions. We used multivariable logistic and linear regression to determine the associations between sociodemographic characteristics, health variables and high sedentary behaviour ( $\geq 8 \mathrm{~h} /$ day) and total minutes of sedentary behaviour a day. No collinearity was detected. Missing data were excluded from the analysis. All results were adjusted for the multistage sampling design.

\section{Ethical consideration}

The study protocol was approved by the research ethics committee (REC) of the HSRC (REC 6/16/11/11).

\section{Results}

\section{Sample characteristics}

From a total sample of 15085 persons aged 15 years and older, 2849 adolescents and adults (mean age $=37.1$ years, standard deviation [s.d.] = 15.1) had been identified as hazardous, harmful or dependent drinkers (or problem drinkers). In the sample of problem drinkers, the prevalence of high sedentary behaviour ( $\geq 8 \mathrm{~h} /$ day) was $11.9 \%(11.9 \%$ among men and $12.1 \%$ among women), and the mean (s.d.) duration of sedentary behaviour was 263 (169) $\mathrm{min} /$ day.

Compared with individuals without hazardous, harmful or dependent drinking, the prevalence of high sedentary behaviour $(13.7 \%)$ and the mean duration of sedentary behaviour (267 $\mathrm{min} /$ day) did not significantly differ from persons with hazardous, harmful or dependent drinking $(11.9 \%)(p=0.117)$ and $(263 \mathrm{~min} /$ day $)(p=0.223)$. In the total sample, more men (70.4\%) than women (29.6\%) were hazardous, harmful or dependent drinkers $(p<0.001)$, and drinkers were younger than non-drinkers $(p<0.001)$. Table 1 describes the sample characteristics and prevalence of high sedentary behaviour among problem drinkers.

\section{Associations with sedentary behaviour}

In bivariate analyses, older age, population group, functional disability, cognitive impairment, having hypertension, having had a stroke and PTSD symptoms were correlated with high sedentary behaviour (see Table 1).

In adjusted logistic regression analysis, older age and being Indian or Asian were positively, and having been diagnosed with angina was negatively, associated with high sedentary behaviour, while in linear regression analysis older age, not employed and having had a stroke were positively, and being of mixed race and having angina were negatively, associated with total minutes of sedentary behaviour in a day (see Table 2).

\section{Discussion}

This is the first study in Africa to investigate correlates of sedentary behaviour among problem drinkers. The investigation found that among problem drinkers $(N=2849$, mean age $=37.1$ years) the prevalence of high sedentary behaviour was $11.9 \%$ and the mean (s.d.) duration of sedentary behaviour was 263 (169) $\mathrm{min} /$ day; this did not differ significantly with non-problem drinkers. The sedentary behaviour duration among problem drinkers seems to be higher in this study than in a study among hazardous drinkers in six middle-income countries (with a higher mean age $=45.7$ years), including South Africa, with a prevalence of $9 \%$ of high sedentary behaviour and a mean duration of sedentary behaviour of $216 \mathrm{~min}^{7}$

This study found among problem drinkers that sedentary behaviour increased with age and that there were population group differences: Indian or Asian persons had a higher prevalence of high sedentary behaviour than other population groups, and back Africans had a higher total time of sedentary behaviour than the other, especially mixed race people, population groups. In the general adult population, older age was associated with higher sedentary behaviour. ${ }^{13,14,15}$ It is not clear as to why we found such racial or cultural differences, which needs further investigation. In a study among five different ethnic groups in the general population in the Netherlands, no significant ethnic differences were found in objectively measured sedentary behaviour. ${ }^{28}$

In our study, not being employed was a strong predictor of increasing minutes per day sedentary behaviour among problem drinkers. A similar correlation was found in a previous study in six middle-income countries, including South Africa. ${ }^{7}$ It is possible that having a job increases 
TABLE 1: Sample characteristics and prevalence of high sedentary behaviour among problem drinkers $(N=2849)$

\begin{tabular}{|c|c|c|c|c|c|}
\hline \multirow[t]{3}{*}{ Variable } & \multirow{2}{*}{\multicolumn{2}{|c|}{ Sample }} & \multicolumn{3}{|c|}{$\begin{array}{c}\text { Sedentary behaviour } \\
(\geq 8 \mathrm{~h} / \text { day })\end{array}$} \\
\hline & & & \multirow{2}{*}{$\begin{array}{l}\text { No } \\
\%\end{array}$} & \multirow{2}{*}{$\begin{array}{l}\text { Yes } \\
\%\end{array}$} & \multirow{2}{*}{$\frac{\text { Chi-square }}{p}$} \\
\hline & $N$ & $\%$ & & & \\
\hline \multicolumn{6}{|l|}{ Socio-demographic factors } \\
\hline Age (years), $M=37.1$ (s.d. = 15.1) & - & - & - & - & - \\
\hline $15-24$ & 721 & 23.1 & 24.1 & 16.8 & 0.037 \\
\hline $25-44$ & 1266 & 51.1 & 49.9 & 59.2 & - \\
\hline $45-64$ & 722 & 21.7 & 22.0 & 17.8 & - \\
\hline $65+$ & 135 & 4.0 & 4.0 & 6.2 & - \\
\hline Sex & - & - & - & - & - \\
\hline Female & 1015 & 70.4 & 70.8 & 70.4 & 0.918 \\
\hline Male & 1834 & 29.6 & 29.2 & 29.6 & - \\
\hline Population group & - & - & - & - & - \\
\hline Black African & 1746 & 71.3 & 70.4 & 76.6 & 0.011 \\
\hline White people & 186 & 13.6 & 14.1 & 9.3 & - \\
\hline Mixed race people & 813 & 13.6 & 14.2 & 10.1 & - \\
\hline Indian or Asian & 92 & 1.5 & 1.2 & 4.0 & - \\
\hline Employment status & - & - & - & - & - \\
\hline Employed & 1227 & 47.6 & 48.4 & 40.7 & 0.104 \\
\hline Not employed & 1565 & 52.4 & 51.6 & 59.3 & - \\
\hline Residence & - & - & - & - & - \\
\hline Rural & 855 & 28.4 & 29.8 & 26.3 & 0.374 \\
\hline Urban & 1994 & 71.6 & 70.2 & 73.7 & - \\
\hline Health status & - & - & - & - & - \\
\hline Self-rated health status (poor) & 684 & 22.9 & 22.8 & 26.8 & 0.315 \\
\hline Functional disability & 284 & 9.2 & 8.4 & 15.3 & 0.009 \\
\hline Cognitive impairment & 157 & 5.2 & 4.7 & 8.1 & 0.049 \\
\hline Health behaviour & - & - & - & - & - \\
\hline Current tobacco use & 1382 & 47.1 & 48.0 & 45.4 & 0.581 \\
\hline Fruits (less once/day) & 1344 & 45.1 & 45.0 & 49.1 & 0.329 \\
\hline Vegetables (less once/day) & 1266 & 43.8 & 43.3 & 47.2 & 0.374 \\
\hline Hand washing before meals (not always) & 552 & 20.8 & 20.2 & 19.2 & 0.776 \\
\hline Physical health & - & - & - & - & - \\
\hline Bodily pain & 369 & 12.7 & 12.1 & 15.9 & 0.140 \\
\hline Ever had tuberculosis & 246 & 8.5 & 8.2 & 9.6 & 0.532 \\
\hline Hypertension & 468 & 14.7 & 14.1 & 18.4 & $<0.001$ \\
\hline High cholesterol & 101 & 3.8 & 3.3 & 3.9 & 0.674 \\
\hline Diabetes & 106 & 3.0 & 2.9 & 2.3 & 0.536 \\
\hline Stroke & 55 & 1.8 & 1.3 & 4.9 & $<0.001$ \\
\hline Angina & 104 & 4.1 & 4.1 & 4.9 & 0.633 \\
\hline Heart disease & 58 & 1.7 & 1.6 & 2.8 & 0.187 \\
\hline Visual problems & 145 & 4.9 & 4.5 & 7.4 & 0.145 \\
\hline Hearing problems & 50 & 1.3 & 1.1 & 1.3 & 0.765 \\
\hline Mental health & - & - & - & - & - \\
\hline Sleep problem & 288 & 10.9 & 10.3 & 13.7 & 0.199 \\
\hline Psychological distress (20+) & 508 & 17.2 & 16.4 & 22.5 & 0.069 \\
\hline PTSD any of three symptom criteria & 267 & 11.2 & 11.4 & 13.2 & 0.008 \\
\hline
\end{tabular}

PTSD, posttraumatic stress disorder; s.d., standard deviation.

physical activity and may involve active transportation to go to work. ${ }^{7}$ In addition, problem drinking may be more prevalent in the unemployed, can cause unemployment and may reduce chances of getting employed.,29 While in the study ${ }^{7}$ in six middle-income countries older adults living in urban areas were more likely to engage in sedentary behaviour, this study did not find any urban-rural differences.

In bivariate analyses, functional disability and cognitive impairment were associated with high sedentary behaviour among problem drinkers. In agreement with a previous study, ${ }^{5}$ this study also found an association between having
TABLE 2: Associations of socio-demographic and health variables with sedentary behaviour levels among problem drinkers.

\begin{tabular}{|c|c|c|c|c|}
\hline \multirow[t]{2}{*}{ Variable } & \multicolumn{2}{|c|}{$\begin{array}{l}\text { Logistic regression: } \\
\text { Sedentary } \geq 8 \mathrm{~h} / \text { day }\end{array}$} & \multicolumn{2}{|c|}{$\begin{array}{l}\text { Linear regression: } \\
\text { Minutes per day sedentary }\end{array}$} \\
\hline & AOR & $95 \% \mathrm{Cl}$ & b-Coefficient & $95 \% \mathrm{Cl}$ \\
\hline \multicolumn{5}{|l|}{ Socio-demographic factors } \\
\hline Age (years) & - & - & - & - \\
\hline $15-24$ & 1 & Reference & - & Reference \\
\hline $25-44$ & 2.44 & $1.44-4.13 * * *$ & 14.65 & $1.89-26.70 *$ \\
\hline $45-64$ & 1.42 & $0.72-2.81$ & 16.70 & $1.52-30.60 *$ \\
\hline $65+$ & 2.43 & $1.01-6.15^{*}$ & 46.92 & $18.55-75.34 * * *$ \\
\hline Sex & - & - & - & - \\
\hline Female & 1 & Reference & - & Reference \\
\hline Male & 1.10 & $0.75-1.64$ & 7.19 & $-1.58-15.96$ \\
\hline Population group & - & - & - & - \\
\hline Black African & 1 & Reference & - & Reference \\
\hline White people & 0.84 & $0.36-1.94$ & -9.71 & $-33.06-13.66$ \\
\hline Mixed race people & 0.70 & $0.43-1.15$ & -26.08 & $-43.73--9.07 * *$ \\
\hline Indian or Asian & 3.40 & $1.72-6.72 * * *$ & -17.07 & $-48.16-14.21$ \\
\hline Employment status & - & - & - & - \\
\hline Employed & 1 & Reference & - & Reference \\
\hline Not employed & 1.38 & $0.69-2.74$ & 28.77 & $14.86-42.68 * * *$ \\
\hline Residence & - & - & - & - \\
\hline Rural & 1 & Reference & - & Reference \\
\hline Urban & 1.26 & $0.75-2.13$ & 9.38 & $-16.88-35.63$ \\
\hline Health status & - & - & - & - \\
\hline Self-rated health status (poor) & 1.03 & $0.60-1.78$ & 1.17 & $-12.71-15.06$ \\
\hline Functional disability & 1.80 & $0.94-3.42$ & 6.69 & $-13.71-27.13$ \\
\hline Cognitive impairment & 1.02 & $0.42-2.48$ & 1.55 & $-6.18-9.29$ \\
\hline Health behaviour & - & - & - & - \\
\hline Current tobacco use & 0.74 & $0.49-1.11$ & -3.22 & $-14.57-8.14$ \\
\hline Fruits (less once/day) & 1.07 & $0.69-1.65$ & 7.93 & $-6.68-22.53$ \\
\hline Vegetables (less once/day) & 1.05 & $0.71-1.57$ & -4.92 & $-19.93-10.09$ \\
\hline $\begin{array}{l}\text { Hand washing before meals } \\
\text { (not always) }\end{array}$ & 0.96 & $0.56-1.67$ & 10.00 & $-6.62-26.63$ \\
\hline Physical health & - & - & - & - \\
\hline Bodily pain & 1.37 & $0.69-2.74$ & 1.46 & $-14.81-17.75$ \\
\hline Ever had tuberculosis & 1.08 & $0.58-2.00$ & 3.86 & $-12.88-20.55$ \\
\hline Hypertension & 1.59 & $0.91-2.78$ & 14.25 & $-0.42-23.25$ \\
\hline High cholesterol & 0.67 & $0.21-2.16$ & 3.31 & $-28.83-34.75$ \\
\hline Diabetes & 0.54 & $0.20-1.45$ & -13.78 & $-34.84-7.28$ \\
\hline Stroke & 2.94 & $0.81-10.71$ & 44.17 & $10.39-77.59 * *$ \\
\hline Angina & 0.28 & $0.08-0.93 *$ & -27.04 & $-50.75--3.33 *$ \\
\hline Heart disease & 1.12 & $0.32-3.92$ & -2.55 & $-36.21-31.11$ \\
\hline Visual problems & 1.29 & $0.58-2.84$ & -8.81 & $-35.22-17.95$ \\
\hline Hearing problems & 0.99 & $0.25-3.85$ & 30.88 & $-26.53-88.30$ \\
\hline Mental health & - & - & - & - \\
\hline Sleep problem & 0.94 & $0.44-2.02$ & -11.98 & $-29.71-4.63$ \\
\hline Psychological distress $(20+)$ & 1.22 & $0.67-2.22$ & 5.00 & $-14.52-24.52$ \\
\hline $\begin{array}{l}\text { PTSD any of three symptom } \\
\text { criteria }\end{array}$ & 0.97 & $0.55-1.69$ & 2.29 & $-19.66-24.25$ \\
\hline
\end{tabular}

$\mathrm{AOR}$, adjusted odds ratio; $\mathrm{Cl}$, confidence interval; PTSD, posttraumatic stress disorder. $* * * p<0.001 ; * * p<0.01 ; * p<0.05$

had a stroke and spending more time in sedentary behaviour among problem drinkers. Contrary to expectation and previous studies, ${ }^{30,31}$ this study found a negative association between angina and sedentary behaviour. It is possible that the individuals with angina have been attending a cardiac rehabilitation programme that includes the promotion of physical activity. A previous review ${ }^{32}$ has shown that increasing physical activity can promote healthy ageing (functional ability), possibly also preventing or delaying functional disability and cognitive impairment. In a community survey in Cape Town, South Africa, stroke 
survivors were found to engage in a high amount of sedentary time. ${ }^{33}$ For people who have had a stroke to engage in physical activity may not be easy, but it would be important to develop possible ways of undertaking physical activity in this population. ${ }^{7}$ On the contrary, problem drinking increases the risk of getting a stroke. ${ }^{5}$

Our findings seem to show that helping problem drinkers to get employment may be a relevant strategy to decrease sedentary behaviour. ${ }^{7}$ An increase in physical activity may also improve the mental and physical health of the problem drinkers. ${ }^{7}$ Furthermore, one may need to consider sociodemographic factors such as age and population group and having chronic conditions, such as stroke, in designing interventions in problem drinkers. Strategies to combine interventions to decrease sedentary behaviour with decreasing problem drinking could be effective and should be tested.

\section{Study limitations}

The study variables, such as sedentary behaviour, alcohol use and physical illness conditions, were self-reported, and the cross-sectional nature of the study limits our ability to establish causality. Longitudinal studies on sedentary behaviour among problem drinkers are warranted.

\section{Conclusion}

This investigation found among problem drinkers that older age, being Indian or Asian, not employed and having had a stroke were positively, and being of mixed race and having been diagnosed with angina were negatively, associated with high sedentary behaviour and/or with total minutes of sedentary behaviour in a day. Findings provide information on possible future interventions that can help to reduce sedentary behaviour among problem drinkers.

\section{Acknowledgements Competing interests}

The authors have declared that no competing interests exist.

\section{Authors' contributions}

K.P., N.P.-M. and S.P. designed the study. K.P. analysed the data and wrote the draft article. All authors read and approved the final manuscript.

\section{Funding information}

This research analysis received no specific grant from any funding agency in the public, commercial or not-for-profit sectors.

\section{Disclaimer}

The views and opinions expressed in this article are those of the authors and do not necessarily reflect the official policy or position of any affiliated agency of the authors.

\section{Data availability statement}

Data are available at http:/ / datacuration.hsrc.ac.za /

\section{References}

1. GBD 2015 Risk Factors Collaborators. Global, regional, and national comparative risk assessment of 79 behavioural, environmental and occupational, and metabolic risks or clusters of risks, 1990-2015: A systematic analysis for the Global Burden of Disease Study 2015. 2015;388(10053):1659-1724. https://doi. org/10.1016/S0140-6736(16)31679-8

2. Schneider $M$, Norman $R$, Parry C, et al. Estimating the burden of disease attributable to alcohol use in South Africa in 2000. S Afr Med J. 2007;7(8 Pt2):664-672.

3. Peltzer K, Davids A, Njuho P. Alcohol use and problem drinking in South Africa: Findings from a national population-based survey. Afr J Psychiatry. 2011;14(1): 30-37. https://doi.org/10.4314/ajpsy.v14i1.65466

4. Vellios NG, Van Walbeek CP. Self-reported alcohol use and binge drinking in South Africa: Evidence from the National Income Dynamics Study, 2014-2015. S Afr Med J. 2017;108(1):33-39. https://doi.org/10.7196/SAMJ.2017.v108i1.12615

5. Patra J, Taylor B, Irving $\mathrm{H}$, et al. Alcohol consumption and the risk of morbidity and mortality for different stroke types - A systematic review and meta-analysis. BMC Public Health. 2010;10:258. https://doi.org/10.1186/1471-2458-10-258

6. Rehm J. The risks associated with alcohol use and alcoholism. Alcohol Res Health. 2011;34(2):135-143.

7. Vancampfort D, Stubbs B, Hallgren M, et al. Correlates of sedentary behaviour among adults with hazardous drinking habits in six low- and middle-income countries. Psychiatry Res. 2018;261:406-413. https://doi.org/10.1016/j.psychres. 2018.01.025

8. Hallgren M, Vancampfort D, Giesen ES, Lundin A, Stubbs B. Exercise as treatment for alcohol use disorders: Systematic review and meta-analysis. Br J Sports Med. 2017;51(14):1058-1064. https://doi.org/10.1136/bjsports-2016-096814

9. Sedentary Behaviour Research Network. Letter to the editor: Standardized use of the terms 'sedentary' and 'sedentary behaviours'. Appl Physiol Nutr Metab. 2012;37(3):540-542. https://doi.org/10.1139/h2012-024

10. Chau JY, Grunseit AC, Chey T, et al. Daily sitting time and all-cause mortality: A meta-analysis. PLoS One. 2013;8(11):e80000. https://doi.org/10.1371/journal. pone.0080000

11. De Rezende LF, Rodrigues Lopes M, Rey-López JP, Matsudo VK, Luiz Odo C. Sedentary behavior and health outcomes: An overview of systematic reviews. PLoS One. 2014;21;9(8):e105620. https://doi.org/10.1371/journal.pone.0105 620. eCollection 2014 .

12. Thorp AA, Owen N, Neuhaus M, Dunstan DW. Sedentary behaviors and subsequent health outcomes in adults a systematic review of longitudinal studies, 1996-2011. Am J Prev Med. 2011;41(2):207-215. https://doi.org/10.1016/j. amepre.2011.05.004

13. Rhodes RE, Mark RS, Temmel CP. Adult sedentary behavior: A systematic review. Am J Prev Med. 2012;42(3):e3-e28. https://doi.org/10.1016/j.amepre. 2011.10.020

14. O'Donoghue G, Perchoux C, Mensah K, et al. A systematic review of correlates of sedentary behavior in adults aged 18-65 years: A socio-ecological approach. BMC Public Health. 2016;16:163. https://doi.org/10.1186/s12889-016-2841-3

15. Stierlin AS, De Lepeleere S, Cardon G, et al. A systematic review of determinants of sedentary behavior in youth: A DEDIPAC-study. Int J Behav Nutr Phys Act. 2015;12:133. https://doi.org/10.1186/s12966-015-0291-4

16. Chastin SF, Buck C, Freiberger E, et al. Systematic literature review of determinants of sedentary behavior in older adults: A DEDIPAC study. Int J Behav Nutr Phys Act. 2015;12:127. https://doi.org/10.1186/s12966-015-0292-3

17. Teychenne M, Costigan SA, Parker K. The association between sedentary behavior and risk of anxiety: A systematic review. BMC Public Health. 2015;15:513. https:// doi.org/10.1186/s12889-015-1843-x

18. Shisana O, Labadarios D, Rehle T, et al. South African National Health and Nutrition Examination Survey (SANHANES-1). Cape Town: Human Sciences Research Council Press; 2013.

19. Prince SA, LeBlanc AG, Colley RC, Saunders TJ. Measurement of sedentary behavior in population health surveys: A review and recommendations. Peer $J$. 2017;5:e4130. https://doi.org/10.7717/peerj.4130. eCollection 2017.

20. Peltzer K, Phaswana-Mafuya N, Pengpid S. Prevalence and correlates of sedentary behaviour among a national sample of $15-98$ years old individuals in South Africa. Afr J Phys Act Health Sci. 2018;24(3):286-298.

21. Bennie JA, Chau JY, Van der Ploeg HP, Stamatakis E, Do A, Bauman A. The prevalence and correlates of sitting in European adults - A comparison of 32 Eurobarometer-participating countries. Int J Behav Nutr Phys Act. 2013;10(1):107. Eurobarometer-participating countries. Int J
https://doi.org/10.1186/1479-5868-10-107

22. Bush K, Kivlahan DR, McDonell MB, et al. The AUDIT alcohol consumption questions (AUDIT-C): An effective brief screening test for problem drinking. Ambulatory Care Quality Improvement Project (ACQUIP). Alcohol Use Disorders Identification Test. Arch Intern Med. 1998;158:1789-1795. https://doi.org/10. Identification Test. Arch Int
1001/archinte.158.16.1789

23. Reddy P, Zuma K, Shisana O, Kim J, Sewpaul R. Prevalence of tobacco use among adults in South Africa: Results from the first South African National Health and Nutrition Examination Survey. S Afr Med J. 2015;105(8):648-655. https://doi. org/10.7196/SAMJnew.7932 
24. Stranges S, Tigbe W, Gómez-Olivé FX, Thorogood M, Kandala NB. Sleep problems: An emerging global epidemic? Findings from the INDEPTH WHO-SAGE study Sleep. 2012;35:1173-1181. https://doi.org/10.5665/sleep.2012

25. Kessler RC, Andrews G, Colpe LJ, et al. Short screening scales to monitor population prevalences and trends in non-specific psychological distress. Psycho Med. 2002;32:959-976. https://doi.org/10.1017/S0033291702006074

26. Andersen LS, Grimsrud A, Myer L, et al. The psychometric properties of the K10 and $\mathrm{K} 6$ scales in screening for mood and anxiety disorders in the South African Stress and Health study. Int J Methods Psychiatr Res. 2011;20(4):215-223. https:// doi.org/10.1002/mpr.351

27. Davidson JR, Book SW, Colket JT, et al. Assessment of a new self-rating scale for post-traumatic stress disorder. Psychol Med. 1997;27:153-160. https://doi. org/10.1017/S0033291796004229

28. Loyen A, Nicolaou M, Snijder MB, et al. Objectively measured sedentary time among five ethnic groups in Amsterdam: The HELIUS study. PLoS One. 2017;12(7):e0182077. https://doi.org/10.1371/journal.pone.0182077. eCollection 2017.
29. Henkel D. Unemployment and substance use: A review of the literature (19902010). Curr Drug Abuse Rev. 2011;4(1):4-27. https://doi.org/10.2174/18744737 11104010004

30. Singh RB, Sharma JP, Rastogi V, et al. Prevalence of coronary artery disease and coronary risk factors in rural and urban populations of north India. Eur Heart J. 1997;18(11):1728-1735. https://doi.org/10.1093/oxfordjournals.eurheartj.a015167

31. Evenson KR, Butler EN, Rosamond WD. Prevalence of physical activity and sedentary behavior among adults with cardiovascular disease in the United States. J Cardiopulm Rehabil Prev. 2014;34(6):406-419. https://doi.org/10.1097/ HCR.0000000000000064

32. Daskalopoulou C, Stubbs B, Kralj C, Koukounari A, Prince M, Prina AM. Physica activity and healthy ageing: A systematic review and meta-analysis of longitudina cohort studies. Ageing Res Rev. 2017;38:6-17. https://doi.org/10.1016/j. arr.2017.06.003

33. Joseph C, Conradsson D, Hagströmer M, Lawal I, Rhoda A. Objectively assessed A stroke living in Cape Town, South Africa. Disabil Rehabil. 2018;40(21):2509-2515. https://doi.org/10.1080/09638288.2017.1338761 